\title{
Confronting the beast Using gamification in library strategic planning
}

$\mathbf{S}$ trategic planning is a vital part of a successful library, academic or otherwise. The ability to anticipate and adapt to change in a planned way has been crucial in the library world as technologies have changed not just the way in which libraries function, but the very definition of what a library is. While it is essential, strategic planning is rarely thought of as a fun activity.

During the 2019 summer term, staff and librarians at Emory \& Henry College were laying the groundwork for the library's newest three-tofive-year strategic plan. To prepare library staff, two colleagues, who were interested in creating a series of gamecentric, teambuilding workshops, were encouraged to use their ideas for games to make

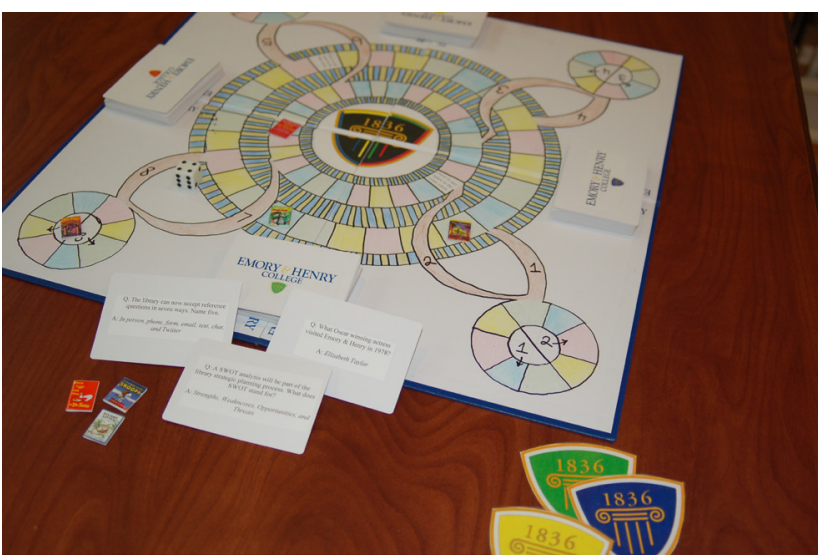

The custom board from the first game. Photo by Adam Alley. and become immersed in an organic dialogue and brainstorming session. By the end of this project, we discovered a number of benefits that gamification can provide in the workplace, including increased participation in group discussions and an overall increase in comfort with sharing ideas, asking questions, and providing criticism.

\section{Project description}

Our initial goal was to create a series of teambuilding games to engage staff, build connections, and boost morale as we moved into a new academic year. The theme for this project was simple: "fun." We delivered our proposal to the director and while encouraging us to pursue a project that engaged the staff, we were directed to focus on an issue or need that was central to the library's current and future operations. This directive meant, while we could still move forward with our "fun

Jody Hanshew is systems and electronic resources librarian, email: jhanshew@ehc.edu, and Adam Alley is tech services specialist at Emory \& Henry College, email: aalley@ehc.edu

(c) 2021 Jody Hanshew and Adam Alley 
activities," we needed to make each one relevant to the workplace. At the time, the entire library staff was creating a strategic plan for the future. Our focus swiftly became consumed with the immense topic of strategic planning. Our new intent became preparing the staff for active participation in the discussions and challenges that come with strategic planning.

We decided to develop five games, one for each session, each focusing on a different aspect of the strategic planning process. As the project developed further, this structure changed somewhat. The first session would include two games, and the last would not focus on a strategic plan topic but would simply be a fun way to wrap up the

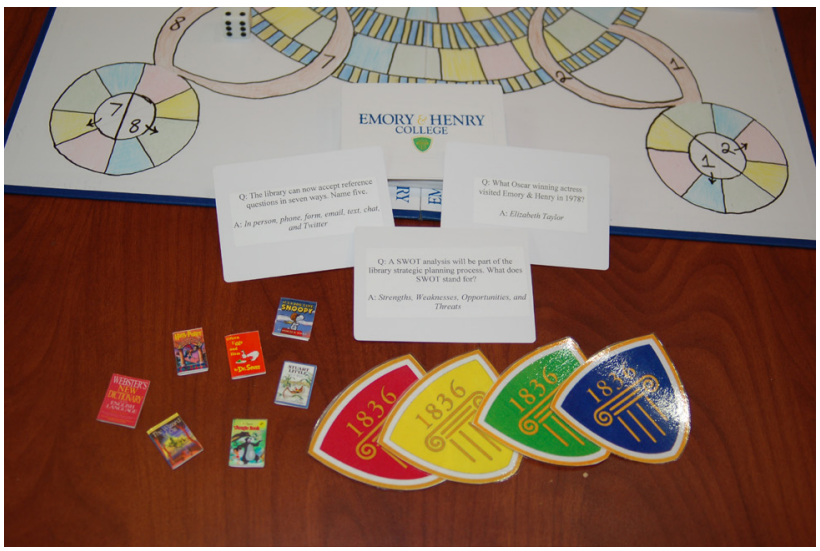

Question cards and game pieces. Photo by Adam Alley. were purchased from Ebay.

\section{Game 2: SWOT}

project.

\section{The games}

\section{Game 1: Emory \& Henry Trivial Pursuit}

This game opened the first strategic planning session and was intended to be an icebreaker. It also served to refresh staff members on library procedures and policies and introduce strategic planning concepts. It was based on Trivial Pursuit, but in place of traditional categories, we used Emory \& Henry History (example: "What all-female school did E\&H merge with in 1918?”), Library Collections and Services ("How long is the book loan period for community borrowers?"), Strategic Planning ("True or false: The phrases 'mission statement' and 'vision statement' are interchangeable."), and Potluck (“True or false: The following was a real reference question asked at E\&H: A patron called needing assistance in identifying the recently deceased bird on her porch"). The game board, question cards, and tokens were created using materials from the library or purchased online. The dice were borrowed from another board game, and the player pieces (miniature books)

This game closed the first strategic planning session (the only one that included multiple games). Our goal was to have a productive brainstorming session for the SWOT analysis that would be assigned afterward. The game began with a brief introduction to SWOT concepts. For four rounds (one for each letter of SWOT), players simultaneously tried to come up with as many strengths, weaknesses, etc., as they could in two minutes, using white boards and markers that we borrowed from the circulation desk. Valid answers received one point while unique answers received two (similar to ThinkBlot or Scattergories).

\section{Game 3: Roles}

The goal for our next session was to create actionable objectives from the SWOT analysis. To help achieve this objective in a natural way, we created a game that would help staff look at the library through the eyes of our stakeholders. In preparation for this game, we created cards that had their names, positions at the institution, and their particular library needs. In each round, one player assumed a role (president, provost, vice president of admissions, vice president of advancement, faculty member, student, community member, etc.). That player prompted the other players with a question card from the top of the deck. (For example: "I am the Dean of Student Success and Retention. Emory \& Henry seeks to improve freshman to sophomore retention. How can the library help to achieve that goal?") The players were given one minute to write down answers on 
small white boards. Then each player took a turn presenting their ideas. The player in the "role" judged them and awarded a point to the player whose idea they deemed worthiest.

\section{Game 4: Library Mission Possible}

The main goal of this game was to help brainstorm ideas for revising the library's mission statement. One player read questions related to the library's mission aloud (for example, "Why does the library exist?" "What image do you want ered Emily Lloyd's Cards Against Librarianship and sprinkled a few of those cards into our decks as well. ${ }^{1}$ We all had so much fun with this game that we played it multiple times throughout the semester.

\section{Reception and participation}

Participation was required as each game corresponded with a scheduled meeting. Regardless of the enforced participation (which did lead to lots of "mandatory fun" jokes), everyone ap-

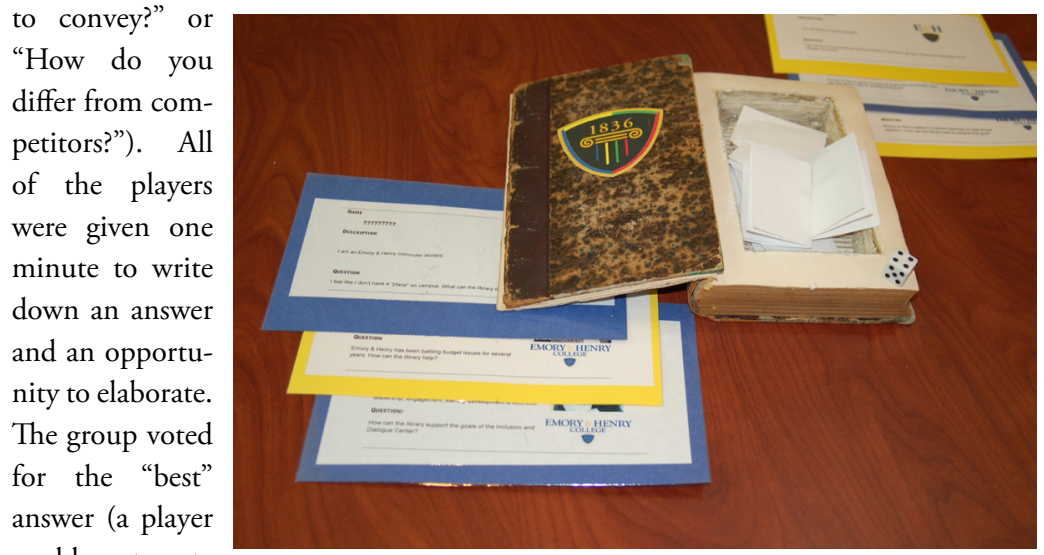

could not vote

for their own

Players selected their "role" by drawing slips of paper from a hollowed out withdrawn book. Photo by Adam Alley. answer), and the

peared to enjoy themselves. We discovered that each game was able to break down communication barriers. As these meetings included the library director, librarians, full-time and part-time staff persons (a variety of employees with a variety of player with the best answer received the point for that round. The secondary goal was to prepare for the final game by creating that game's "answer cards." We did not clue the staff in on this but handed out blank cards that they would fill out by responding to question prompts at the end of each round.

\section{Game 5: Library Cards Against Humanity}

The final game was played after the bulk of the strategic planning work had been done. It was mostly for fun, but we hoped it would also have some team-building benefit and would be an excellent way to wrap up the project. The game itself was a PG-13 rated version of the card game Cards Against Humanity.

To make it interesting, the deck of potential answer cards was created by asking the staff unrelated questions after each round of the previous game. ("Who is your favorite literary villain?" "What is your least favorite food?") Near the end of our preparation work for this game we discov- experience), these games were vital in creating a space for open, judgement-free communication.

\section{What worked and what didn't}

In general, we considered the project to be a success. The games helped open up communication. Each game summarized the topic for the day and prepared staff to be active participants by clarifying the daily objectives, and often they were actually quite enjoyable. The mechanics of the games worked (mostly) as we intended. While there were certainly things we would change in retrospect, there were no major problems.

On the negative side, we did realize that we had frontloaded the best ideas and got less creative and simpler in the game creation as the project progressed. This was due to several factors, including a high workload in that time period that led to a lack of time and a general sense of being worn down. We also realized that some of our initial ideas worked well as a 
game, but less so as a strategic planning teaching tool, or vice versa. This realization led to a few last-minute changes that resulted in some games that were less developed than others.

\section{Lessons learned}

From its initial implementation, this project and the process taken to give it life, offered several important lessons that are applicable, not only to library staff in the middle of creating a strategic plan, but also for librarians wanting to do similar projects and programs in other areas of their institution.

- Time management: One of the most important lessons gleaned from this endeavor was time management. We underestimated the amount of time that creating and playtesting the games for this project would take. As the workload increased it became more difficult to find the time, and, soon enough, we found ourselves overwhelmed and struggling to finish the remaining games. Fatigue and burnout were prevalent nearing the end of this project.

- Collaboration: Input from additional staff can be very valuable. We took advantage of this, but not as much as we could have. One thing we did that was beneficial was using college staff members who were not in the department as play testers on some of the games. This brought some potential problems to light and led to some changes in game mechanics.

- Share directions with the staff beforehand: While most of the games were fairly simple, some had more elaborate rules. It could be beneficial to share these with the staff before the game in one way or another. For our very first game, we made a short video explaining the rules that we shared with staff over email.
- You can do a lot with a small number of resources: We didn't really have a budget for this project, so we tried to use existing materials whenever we could. The whiteboards and markers were borrowed from the circulation desk, and we used the library printer for the games that required printed materials. The most significant expenses were for the first game, which included a blank game board (\$7), blank cards (\$10 per pack), and player tokens (\$1.50 each).

\section{Update and COVID-19's effect on the new plan}

The five-year strategic plan developed during this project was completed and approved by the college administration in May 2020. While the pandemic

has placed numerous delays on library operations, the library staff continues to execute the objectives laid out in the strategic plan. If our gamification project had occurred a few months later than it did, it would have been difficult to implement in exactly the same way. Having said that, many of the games could have been played virtually. As a test (and for a bit of morale building in the midst of the COVID-19 closure of our library) we replayed our last game virtually using both Zoom and PlayingCards.io. ${ }^{2}$ It worked reasonably well, and everyone was eager to enjoy a friendly game of cards with each other.

We discovered the benefits of approaching complex, administrative planning with fun, interactive activities. We also discovered an overall boost in morale, participation, and creativity that can be experienced when communication barriers are broken down and a workspace is created that encourages open discussion,

(continues on page 486) 
in the workplace, with all its challenges and fun. For my LinkedIn posts, no one tells me what to write. It's likely I'll write on other topics in the future. No one is overseeing your writing, which is a bit of a double-edged sword. You don't have anyone telling you what to write, but that means you have to have something to write.

In scholarly publishing, I often feel that I need to "stay in my lane" and continue to research and write in the area of entrepreneurial spaces and ecosystems. When writing for LinkedIn, I can readily publish outside of my field. You can, too. Of course, not everyone is a scholar or has to write peer reviewed articles to get tenure and promotion. LinkedIn is an ideal way to publish and publish a lot, whenever you'd like.

Writing this way, for a larger and more diverse audience, you can build upon your existing reputation. You can also work to develop a reputation in another area. I was recommended to speak on nonbinary workplace inclusion to Mojang Studios because of my LinkedIn posts on the topic. You can explore new topics, learn and write about them, all while not impinging on your current position.

\section{The downsides of Linkedln}

The downsides of LinkedIn are few. I have gotten some sales pitches and sat through some Zoom meetings, which I shouldn't have taken. I have been lucky enough to not have trolls visit and comment on my posts, but some higher profile folx I follow, such as Madison Butler, are constantly trolled and verbally abused. I'm waiting for it to happen, sadly, given my posts are on nonbinary gender and gender nonconformity.

\section{A word of caution}

I'm pushing LinkedIn as a publishing platform, but not as a replacement for publishing peerreviewed journal articles. Your employer may encourage or require you to publish in peer-reviewed journal articles in order to get promoted or to get tenure. My pitch is that LinkedIn gives you other publishing opportunities outside of traditional scholarly publishing.

\section{Posts versus articles}

On LinkedIn you have the option to publish standalone articles or post to your feed. Not many people read my articles. The two most viewed articles, "My Gender Journey at Work" parts one and two, have 339 and 157 views respectively. Many more people looked at my posts. Sometimes hundreds of people. Sometimes thousands of people. One of my posts, about coming out at work as nonbinary has 5,307 views, and most posts have more than 400 views. The impact and reach are likely greater than the scholarly articles I write and get published, which get put behind a publisher's pay wall.

\section{Final points}

Getting better at writing takes practice. It also helps to write for an audience. Writing and posting on LinkedIn gives you both: an opportunity to write as often as you like and to write for your network. It also gives you a chance to write outside of the confines of scholarly publications and without barriers to publishing. It is easy to explore and write about new topics, and to engage directly with your readers. And finally, writing for LinkedIn is really fun. Try writing a LinkedIn post and see what happens. 2

("Confronting the beast," continued from page 480)

reflection, and goofy behavior. Moving forward, we can see the usefulness of gamification in many areas of the library, though more research into this area of study is needed. Whether you are interested in gamifying a large project like strategic planning or just setting aside some time at lunch for staff members to gather (in person or virtually) we encourage you to integrate gaming into your workplace. And above all, have fun.

\section{Notes}

1. Emily Lloyd, "Cards Against Librarianship: Let's Play!” Shelf Check, January 21, 2014, http://shelfcheck. blogspot.com/2014/01/cards-against-librarianship-lets -play.html.

2. "PlayingCards.io," PlayingCards.io Virtual Tabletop, accessed March 19, 2021, https://playingcards.io/. 22 